\title{
Creep behaviour of plane frame structures made of GFRP profiles
}

\author{
M. Seçer*, M.E. Kural** \\ *Izmir Katip Celebi University, Balatcik Campus, 35620, Cigli, Izmir, Turkey, E-mail: mutlu.secer@ikc.edu.tr \\ **Dokuz Eylul University, Tinaztepe Campus, 35397, Buca, Izmir, Turkey, E-mail: emin.kural@deu.edu.tr \\ cross $^{\text {ref }}$ http://dx.doi.org/10.5755/j01.mech.23.3.14029
}

\section{Introduction}

Glass Fiber Reinforced Polymer (GFRP) composite structural shapes manufactured by the pultrusion process have grown rapidly in the civil engineering industry in recent years [1]. These types of composite materials have been improved by progress in technology and started to be investigated from all perspectives [2]. GFRP profiles made from pultrusion process are frequently used as a design alternative where significant corrosion protection and chemical resistance is required [3]. Likewise, where accessibility is limited and lightweight structures are essential $[4,5]$ or where electromagnetic transparency is necessary, the pultruded GFRP profiles have come forward. Beside, their high strength to weight ratios, GFRP profiles can be used together with other construction materials accounting their benefits for improving the structural behaviour [6]. Since GFRP profiles can be produced in number of different section shapes similar to those used in the steel structures by several manufacturers around the world and can be cut to any desired length, it became an alternative material for the structural design [1]. However, beside these advantages, GFRP profiles are viscoelastic and show timedependent behaviour. This issue is a disadvantage for the GFRP profiles which is required to be studied $[1,7]$.

In the literature, there are limited numbers of long-term tests for pultruded GFRP materials exist which is not sufficient to assess the creep behaviour of pultruded GFRP structures from different perspectives. Tests for time-dependent behaviour of GFRP profiles under static loads are often performed by coupon tests [8-10] and limited studies are performed on full-scale structures that are formed by pultruded GFRP profiles [11]. However, coupon tests are practical and cost-effective for investigating the time-dependent behaviour whereas full-scale tests provide more realistic results for determining the structural performance. In support of investigating time-dependent behaviour of structures that are formed with pultruded GFRP profiles, more studies are required to be performed for obtaining time-dependent strain redistributions within the cross-section of structural systems.

In this study, an analytical method is presented to investigate the creep behaviour of plane frame structures that are made of GFRP profiles under sustained loads and a full-scale test is performed using plane frame structure that is constructed using pultruded GFRP profiles and test results are compared with numerical analysis outcomes. In full-scale test frame, static load is applied from midpoint of the beam of the frame structure for 100 days and beam midpoint deflection and strains for particular points of the frame are monitored. Analytical results and test data are compared and satisfactory outcomes are observed.

\section{Stress - strain - time relationship of viscoelastic structures}

Stress - strain - time relationship for nonlinear viscoelastic material is accounted as below [12]:

$$
\sigma(t)=\varepsilon_{0}\left\{B_{0}\left(\varepsilon_{0}\right)+\sum_{i=1}^{n} B_{i}\left(\varepsilon_{0}\right) g_{i}(t)\right\},
$$

where $\sigma(t)$ is time-dependent stress function; $B_{i}(\varepsilon)$ is mechanical properties of the material related to deformation level; $g_{i}(t)$ is time function selected to reflect the behaviour. $B_{i}(\varepsilon)$ and $g_{i}(t)$ functions are shown as in Eq. (2) and Eq. (3), respectively.

$$
\begin{aligned}
& B_{i}(\varepsilon)=k_{i}|\varepsilon|^{p_{i}-1} ; \\
& g_{i}(t)=e^{-t / \lambda_{i}},
\end{aligned}
$$

where $t$ is time, $k_{i}, p_{i}$ and $\lambda_{i}$ are material properties, $\varepsilon$ is strain. Similarly, for variable strain Eq. (1) is written as Eq. (4) [12]:

$$
\begin{aligned}
& \sigma(t)=\varepsilon(t)\left\{B_{0}(\varepsilon(t))+\sum_{i=1}^{n} B_{i}(\varepsilon(t))\right\}- \\
& -\sum_{i=1}^{n} \int_{0^{+}}^{t} \varepsilon(\tau) B_{i}(\varepsilon(\tau)) \frac{\partial}{\partial \tau} g_{i}(t-\tau) d \tau .
\end{aligned}
$$

If $g_{i}(t)$ is equal to unity and $B_{i}(\varepsilon)$ is accounted as constant for Eq. (4), then Hooke law as given in Eq. (5) can be obtained:

$$
\sigma(t)=\varepsilon(t)\left\{B_{0}+\sum_{i=1}^{n} B_{i}\right\}=E \varepsilon(t)
$$

Likewise, if $\beta_{i}$ is assumed as linear viscoelastic and the mechanical properties as deformation level $B_{i}(\varepsilon)=\beta_{i}=$ constant,$\quad \psi(0)=\beta_{0}+\sum_{i=1}^{n} \beta_{i} \quad$ and $\psi(t)=\beta_{0}+\sum_{i=1}^{n} \beta_{i} g(t)$ are written in Eq. (4), then Boltzmann superposition principle can be achieved as Eq. (6):

$$
\sigma(t)=\varepsilon(t) \psi(0)-\int_{0^{+}}^{t} \varepsilon(\tau) \sum_{i=1}^{n} \beta_{i} \frac{\partial}{\partial \tau} g_{i}(t-\tau) d \tau .
$$




\section{Application of moment-curvature relationship to a frame member}

Stress and moment functions are derived by using strain and curvature relationship given in Eq. (7). Since stress - strain - time relation is given in Eq. (4), stress and moment functions are derived as in Eq. (8) and Eq. (9) as follows:

$$
\varepsilon(t)=-z \frac{\partial^{2} \Omega(t)}{\partial x^{2}}=-z \Omega_{x}(t) ;
$$

$$
M=\int_{A}\left[\left(-z \Omega_{x}(t)\right)\left\{B_{0}\left(-z \Omega_{x}(t)\right)+\sum_{i=1}^{n} B_{i}\left(-z \Omega_{x}(t)\right)\right\}-\sum_{i=1}^{n} \int_{0^{+}}^{t}\left(-z \Omega_{x}(\tau)\right) B_{i}\left(-z \Omega_{x}(t)\right) \frac{\partial}{\partial \tau} g_{i}(t-\tau) d \tau\right] z d A,
$$

Eq. (10) into the equations, moment - curvature relationship can be calculated using Eq. (11). In order to calculate curvature for a section from a moment value, Eq. (11) is written as in Eq. (12):

$$
I_{p i}=2 b /\left(p_{i}+2\right)(d / 2)^{p_{i}+2}
$$

$$
\begin{gathered}
M=-E I_{0} \Omega_{x}(t)+k_{0} \Omega_{x}(t)\left|\Omega_{x}(t)\right|^{p_{0}-1} I_{p_{0}}-\Omega_{x}(t) \sum_{i=1}^{n} k_{i}\left|\Omega_{x}(t)\right|^{p_{i}-1} I_{p_{i}}+\sum_{i=1}^{n} \frac{k_{i} e^{-t / \lambda_{i}}}{\lambda_{i}} I_{p_{i}} \int_{0^{+}}^{t} \Omega_{x}(\tau)\left|\Omega_{x}(\tau)\right|^{p_{i}-1} e^{\tau / \lambda_{i}} d \tau ; \\
\Omega_{x}(t)=\frac{-M}{\left[E I_{0}-k_{0}\left|\Omega_{x}(t)\right|^{p_{0}-1} I_{p_{0}}+\sum_{i=1}^{n} k_{i}\left|\Omega_{x}(t)\right|^{p_{i}-1} I_{p_{i}}-\frac{1}{\Omega_{x}(t)} \sum_{i=1}^{n} \frac{k_{i} e^{-t / \lambda_{i}}}{\lambda_{i}} I_{p_{i}} \int_{0^{+}}^{t} \Omega_{x}(\tau)\left|\Omega_{x}(\tau)\right|^{p_{i}-1} e^{\tau / \lambda_{i}} d \tau\right]},
\end{gathered}
$$

where $M$ bending moment; $t$ time; $k_{i}$ material coefficients; $E$ modulus of elasticity; $b$ width of section; $d$ height of section; $p_{i}$ material coefficient; $I_{0}$ is moment of inertia of the section; $I_{p i}$ is a value that is related with section properties and $\Omega_{x}(t)$ is time-dependent curvature function.

Moment curvature relationship is calculated on the first step for the time-dependent analysis of viscoelastic frame system. Viscoelastic frame member with member length $L_{c}$ is assumed and the moment value for any arbitrary section in $0 \leq x \leq L_{c}$ is known, then curvature is determined as in Eq. (12). In order to have more general form, Eq. (12) is written for different sections of $x=0,1,2, \ldots, k \Delta x$ and curvature at any section of frame member for any time is defined by Eq. (13):

$$
\begin{aligned}
& \Omega_{x}^{x}(k \Delta x, r \Delta t)=-M(x, t) /\left\{E I_{0}-k_{0}\left|\Omega_{x}^{m}(k \Delta x, r \Delta t)\right|^{p_{0}-1} I_{p_{0}}+\sum_{i=1}^{n} k_{i}\left|\Omega_{x}^{m}(k \Delta x, r \Delta t)\right|^{p_{i}-1} I_{p_{i}}-\right. \\
& -1 / \Omega_{x}^{m}(k \Delta x, r \Delta t) \sum_{i=1}^{n} \frac{k_{i}}{\lambda_{i}} e^{-r \Delta t / \lambda_{i}} I_{p_{i}} \frac{\Delta T}{2}\left[\Omega_{x}(k \Delta x, 0)\left|\Omega_{x}(k \Delta x, 0)\right|^{p_{i}-1}+\right. \\
& \left.\left.+2 \sum_{j=1}^{s-1} \Omega_{x}(k \Delta x, j \Delta t)\left|\Omega_{x}(k \Delta x, j \Delta t)\right|^{p_{i}-1} e^{j \Delta t / \lambda_{i}}+\Omega_{x}^{m}(k \Delta x, r \Delta t)\left|\Omega_{x}^{m}(k \Delta x, r \Delta t)\right|^{p_{i}-1} e^{r \Delta t / \lambda_{i}}\right]\right\},
\end{aligned}
$$

where $m$ iteration number; $k$ section number; $r$ number of time interval; $\Delta x$ and $\Delta t$ change in location and time. In Eq. (13), curvature without a superscript $\Omega_{x}$ means that it's real value that is calculated before and remains same during the iteration. Similarly, if curvature with a superscript $\Omega_{x}^{m}$ is the investigated curvature value and $\Omega_{x}^{x}$ is the new curvature value after iteration.

Curvature value at any section at any time can be calculated using the moment values and Eq. (13). In order to calculate rotation values for a frame member as given in Fig. 1, moment value for an arbitrary section is determined by Eq. (14):

$$
M(x, t)=M_{j}(t)-\frac{M_{j}(t)+M_{k}(t)}{L_{c}} x,
$$

where $M_{j}(t)$ and $M_{k}(t)$ are end moment values for the time, $L_{c}$ is length of frame member, $x$ is location and $t$ is time.

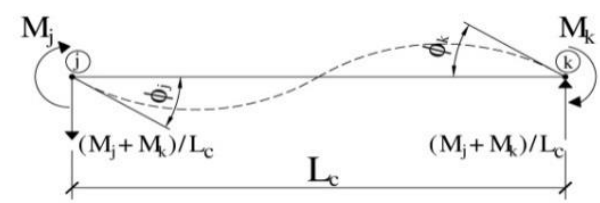

Fig. 1 Frame member

Virtual work is given as Eq. (15) and it is used for determination of end rotations for a member:

$$
1 \times \phi_{j}(t)=\int_{V} \varepsilon \sigma_{v} d V
$$


where $\phi_{j}(\mathrm{t})$ is time-dependent rotation at $j$ end; $\varepsilon$ strain; $\sigma_{v}$ is stress for virtual system; $V$ is volume.

Eq. (7), Eq. (8) and Eq. (12) are put into Eq. (15) and consequently Eq. (16) is obtained. Integral that is in Eq. (16) is similar with Eq. (11) and this is accounted as virtual moment on the arbitrary section of the frame and Eq. (16) is derived as Eq. (17). Virtual moment is written into Eq. (17) for $j$. and $k$. ends of the member and Eq. (18) and Eq. (19) are obtained accordingly.

$$
\begin{aligned}
& 1 \times \phi_{j}(t)=\int_{0^{+}}^{L_{c}}-\Omega_{x}(x, t)\left\{\int _ { A } z \left\{-z \Omega_{x}(x, t)\left[E-k_{0}\left|-z \Omega_{x}(x, t)\right|^{p_{0}-1}+\sum_{i=1}^{n} k_{i}\left|-z \Omega_{x}(x, t)\right|^{p_{i}-1}\right]-\right.\right. \\
& \left.\left.-\sum_{i=1}^{n} \frac{k_{i}}{\lambda_{i}} e^{-t / \lambda_{i}} \int_{0^{+}}^{t}-z \Omega_{x}(x, \tau)\left|-z \Omega_{x}(x, \tau)\right|^{p_{i}-1} e^{\tau / \lambda_{i}} d \tau\right\} d A\right\} d x
\end{aligned}
$$

$$
\begin{aligned}
& 1 \times \phi_{j}(t)=-\int_{0^{+}}^{L_{c}} \Omega_{x}(x, t) m_{v}(x) d x ; \\
& \phi_{j}(t)=-\int_{0^{+}}^{L_{c}}\left(1-\frac{x}{L_{c}}\right) \Omega_{x}(x, t) d x ; \\
& \phi_{k}(t)=\int_{0^{+}}^{L_{c}} \frac{x}{L_{c}} \Omega_{x}(x, t) d x,
\end{aligned}
$$

where $\Omega_{x}(x, t)$ location and time-dependent curvature; $\phi_{j}$ (t) and $\phi_{k}(t)$ are time-dependent end rotations for $j$ and $k$ ends of frame member; $L_{c}$ length of the member; $E$ modulus of elasticity; $x$ location; $t$ time; $z$ distance to neutral axis; $k_{i}, p_{i}$ and $\lambda_{i}$ material coefficients.

If the end moments of a frame member and loads acting on the frame member are known, curvature is calculated by Eq. (13). Consequently, curvature results are used in Eqs. (18) and (19) in order to calculate end rotations of the frame member. Viscoelastic member is given in form of equivalent linear elastic member and rigidity coefficients of the equivalent linear member are given in Eqs. (20) and (21). In these equations also, member section is accounted constant in the length of the member and in order to have the equation in more general form $\Delta$ displacement term is added.

$$
\begin{aligned}
& M_{j}=s_{1}\left(\theta_{j}(t)-\frac{\Delta}{L_{c}}\right)+s_{2}\left(\theta_{k}(t)-\frac{\Delta}{L_{c}}\right) ; \\
& M_{k}=s_{2}\left(\theta_{j}(t)-\frac{\Delta}{L_{c}}\right)+s_{1}\left(\theta_{k}(t)-\frac{\Delta}{L_{c}}\right),
\end{aligned}
$$

where $M_{j}$ and $M_{k}$ are moment values for the $j$ and $k$ ends of the member; $\Delta$ is displacement between frame ends; $L_{c}$ is the length of the member; $\theta_{j}(t)$ and $\theta_{k}(t)$ are time-dependent rotations for the $j$ and $k$ ends of the member; $s_{1}$ and $s_{2}$ are rigidity coefficients of member. These rigidity coefficients are dependent to moment values and are calculated for frame members. The viscoelastic deformation approach is applied for analysis. $M_{i}$ value, which is calculated at the end of calculation, should be equal to the moment value that is accepted to be known prior to the calculation process. However, in the beginning of the calculation, since moment value is not known in advance, a trail $M_{i}{ }^{1}$ value is accepted. For a trail value, linear elastic analysis results can be used. Moment value $M_{i}{ }^{x}$ that is calculated at the end of the calculation, is not equal to $M_{i}{ }^{1}$ accounting a tole- rance value, same process is performed accounting $M_{i}{ }^{2}$ as $M_{i}{ }^{x}$ value and this process is repeated up to the calculated moment value is equal to $M_{i}{ }^{m}$ in adequate tolerance. This process is repeated for $t=0, \Delta t, 2 \Delta t, \ldots, r \Delta t$ and timedependent changes in internal forces and joint displacements of viscoelastic frame system is calculated.

In order to investigate time-dependent behaviour of plane frame structures a computer program is developed using the procedure described in this section. A GFRP frame is modelled and analysed under sustained loads for the time period of 100 days.

\section{Time-dependent tests under sustained loads}

A plane frame that is formed with GFRP profiles is tested for 100 days under sustained loads. Static load is applied from the midpoint of the beam of the frame and strain, displacement values for some selected points are monitored during the test. Likewise, three point beam bending test is performed in order to evaluate the behavior and results of this test is used for determination of material coefficients for the analytical function. In order to perform creep tests and eliminate possible geometric influences on the structural behavior, GFRP profiles are supplied from same stock having same material and section properties [13]. Since, it is important to keep stress level same for determining creep behavior [14], static loads are used instead of hydraulic loading systems to keep the stress level constant during the test period. Time independent mechanical properties of the GFRP profiles are also determined using three point bending test described in ASTM standard [15]. Elasticity modulus is $21058 \mathrm{MPa}$, shear modulus is $855 \mathrm{MPa}$, and flexural strength is $464 \mathrm{MPa}$ for coupons that are taken from GFRP profiles.

Three point bending test of GFRP beam with $40 \mathrm{~mm} \times 40 \mathrm{~mm} \times 4 \mathrm{~mm}$ box section under sustained load is performed at first as shown in Fig. 2. Beam clear length is $3200 \mathrm{~mm}$ and load is applied from the midpoint of the beam and section stress is $23.2 \mathrm{MPa}$.

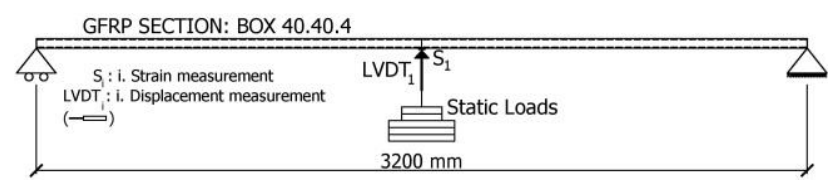

Fig. 2 Three point bending test model for GFRP box beam

Midpoint deflection is monitored by using LVDT and strain value is monitored by strain gauges for timedependent three point bending test for 30 days in Fig. 3 . 


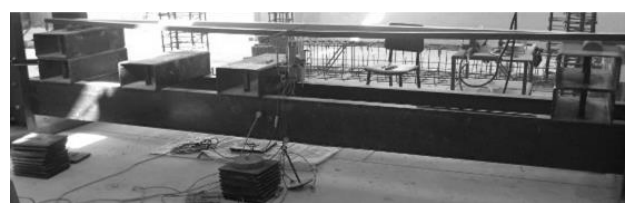

Fig. 3 Three point bending test setup for GFRP beam

A plane frame made of GFRP profiles is used for testing the time-dependent behaviour for 100 days under sustained loads. Static load is applied from the midpoint of the beam member of the plane frame and structural behaviour is monitored during the test with the relevant time intervals. Column and beam members are formed with $40 \mathrm{~mm} \times 40 \mathrm{~mm} \times 4 \mathrm{~mm}$ box GFRP sections as given in Fig. 4. Beam length and column height is $1800 \mathrm{~mm}$. Beam to column connection is made with top-and-seat angles with $\mathrm{L} 100 \mathrm{~mm} \times 10 \mathrm{~mm}$ GFRP section and steel M12 (8.8) bolts are used as shown in Fig. 5. Since connection is formed with relatively high angle sections than beam member as presented in Fig. 6 and relatively low load level is used in the test, the connection behaviour is assumed as rigid. Moreover, a strain-gauge is used at theoretical moment zero location in the test frame and the strain value is controlled for validating rigid connection assumption.

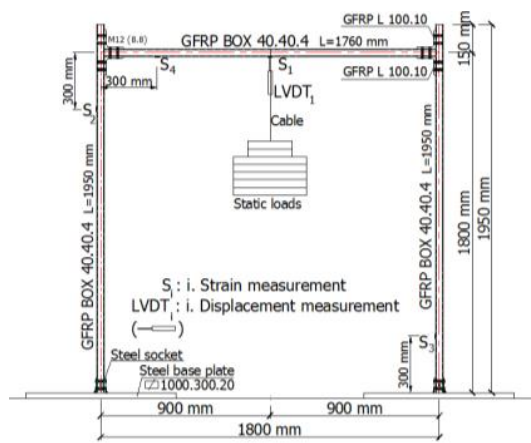

Fig. 4 GFRP frame model

Midpoint deflection of the beam of the frame and strain of four locations on the frame are monitored using LVDT and stain-gauges as given in Fig. 4. Since, it is a characteristic point, midpoint deflection is reported. Besides, strain values are monitored for station points; $S_{1}$ at the midpoint of the beam member of the frame, $S_{2}$ and $S_{3}$ on the column at $300 \mathrm{~mm}$ below the beam-column connection and $300 \mathrm{~mm}$ above the base plate. Also, $S_{4}$ is placed at theoretical zero strain point on the beam.

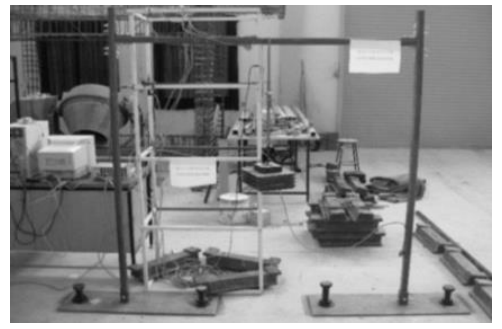

Fig. 5 GFRP frame test setup

Applied load level is selected accounting the serviceability limits of ASCE as L/180 where $L$ is the length of the beam [16]. After loading is performed, the vertical deflection of midpoint of the beam is $10.34 \mathrm{~mm}$. The stress value for this load level is calculated as $21.6 \mathrm{MPa}$ which is approximately $5 \%$ of the beam bending capacity. This value is lower than the $20 \%$ limit which is suggested for GFRP systems in many studies [1].

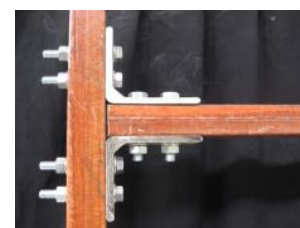

a

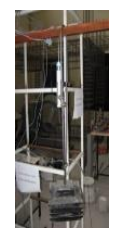

$\mathrm{b}$
Fig. 6 GFRP frame details: a) beam-column connection; b) static loads

This load is kept for 100 days and data is recorded for the time intervals as 10 seconds for the first hour, and hourly readings for remaining 23 hours and daily for following 99 days.

\section{Evaluation of test results with analytical approach}

Test results are evaluated using stress - strain time relationship derived in the analytical part of the study. Material coefficients are determined from time-dependent three point beam bending test and these coefficients are used in analytical solving of one bay frame numerically. Test results of one bay frame are compared with the analytical study results and outcomes are discussed.

In order to determine material coefficients for the analytical approach, three point beam bending test results are used. GFRP beam's midpoint strain and time relation is plotted and nonlinear least-squares method is used for curve fitting as in Fig. 7. Material coefficients are determined as $k_{0}=3482, k_{1}=3505, p_{0}=1.086, p_{1}=1.101$, $\lambda_{1}=11.75$.

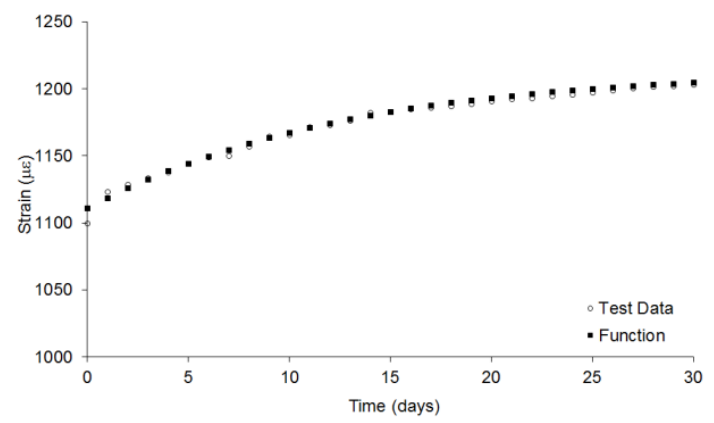

Fig. 7 Midpoint strain - time relationship for three point bending test of beam member

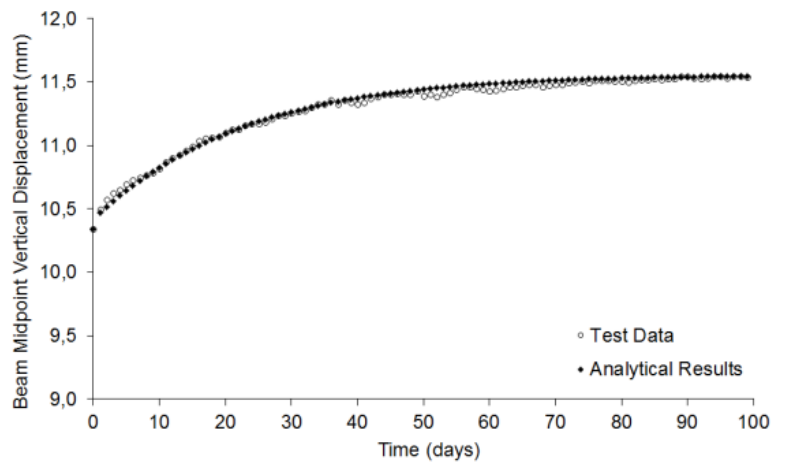

Fig. 8 Vertical displacement of $S_{1}$ point of the frame - time 
Test results and analytical calculations for timedependent behaviour of one bay frame are compared. Vertical deflection of beam midpoint - time graphic is given in Fig. 8, strain - time graphics for selected points on the GFRP frame are presented in Figs. 9-11. Also, analytical calculation results are given for bending moment - time graphics for the selected points in Figs. 12-14.

Increase in the vertical displacement of the midpoint of the frame's beam for 100 days is given in Fig. 8 and determined as $11.5 \%$ and $11.6 \%$ from test and analytical results. Strain of the midpoint of the frame's beam is also monitored and results are presented in Fig. 9. These results show that strain increase for the test period of 100 days for the midpoint of the frame's beam are $12.9 \%$ and $12.8 \%$ for test data and analytical results.

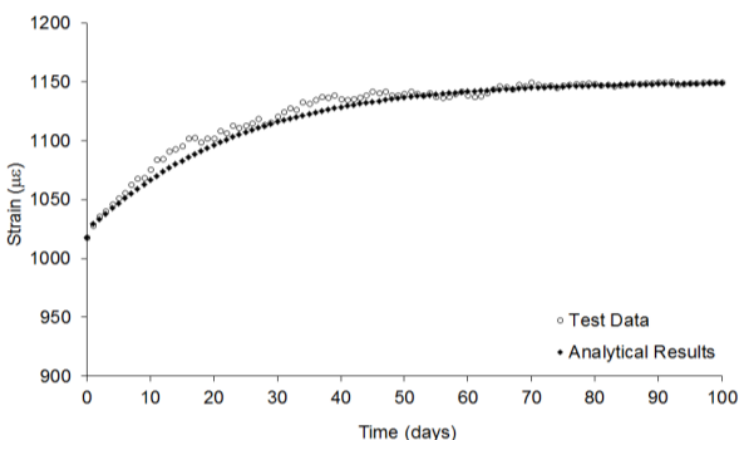

Fig. 9 Strain of $S_{1}$ point of the frame - time

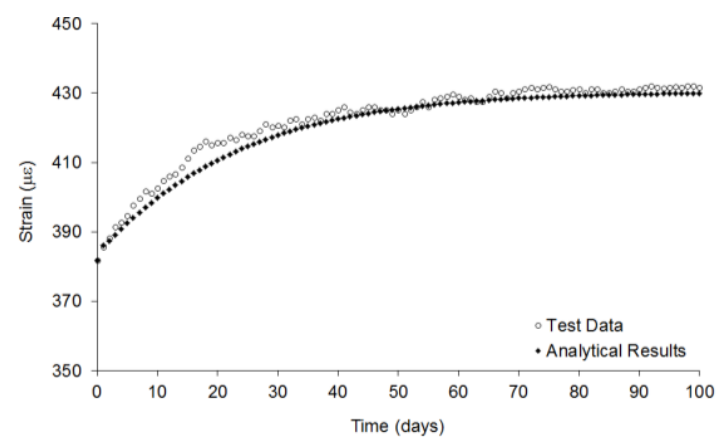

Fig. 10 Strain of $S_{2}$ point of the frame - time

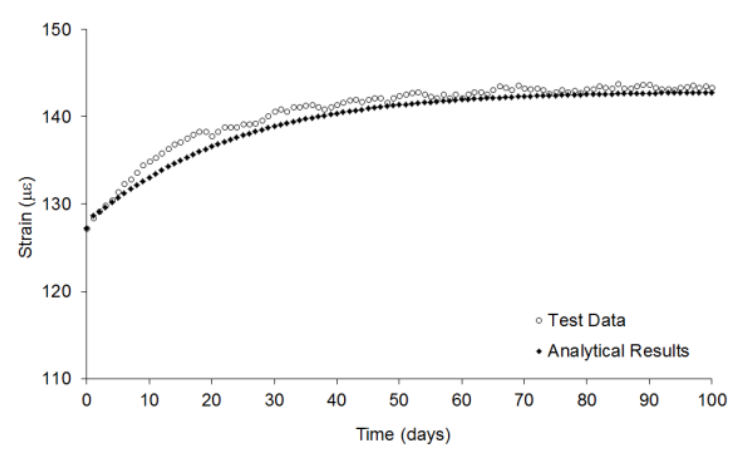

Fig. 11 Strain of $S_{3}$ point of the frame - time

Stain values for $S_{2}$ and $S_{3}$ strain-gauges which are placed on the column at $300 \mathrm{~mm}$ below the beamconnection and $300 \mathrm{~mm}$ over the base plate, are also given in Figs. 10 and 11 for comparing the test data with the analytical results. Strain increase for $S_{2}$ point is $13.1 \%$ and $12.6 \%$ and for $\mathrm{S}_{3}$ point is $12.6 \%$ and $12.2 \%$ for test data and analytical results at the end of the 100 days test. All strain values that are monitored for 100 days show an increase in lowering trend.
Bending moment values are calculated using analytical method for the same sections that strain values are monitored. Bending moment - time relationship for beam midpoint, the column sections at $300 \mathrm{~mm}$ below the beamcolumn connection and $300 \mathrm{~mm}$ above the base plate are presented using analytical calculation results in Figs. 12-14.

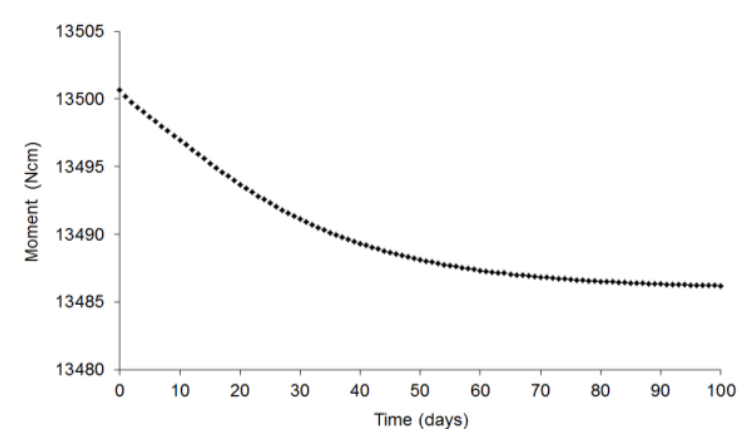

Fig. 12 Bending moment of $S_{1}$ point of the frame - time

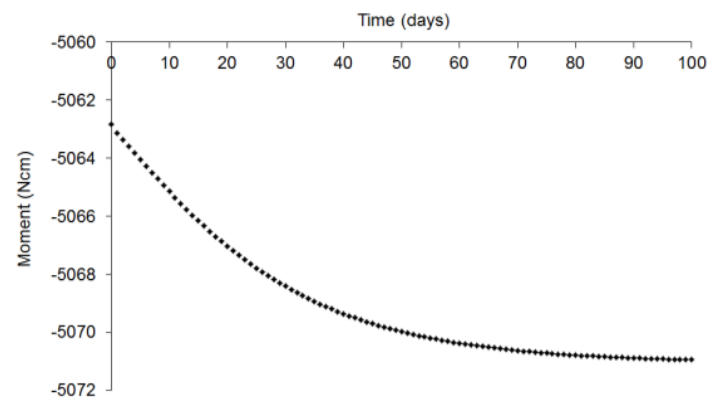

Fig. 13 Bending moment for $S_{2}$ point of the frame - time

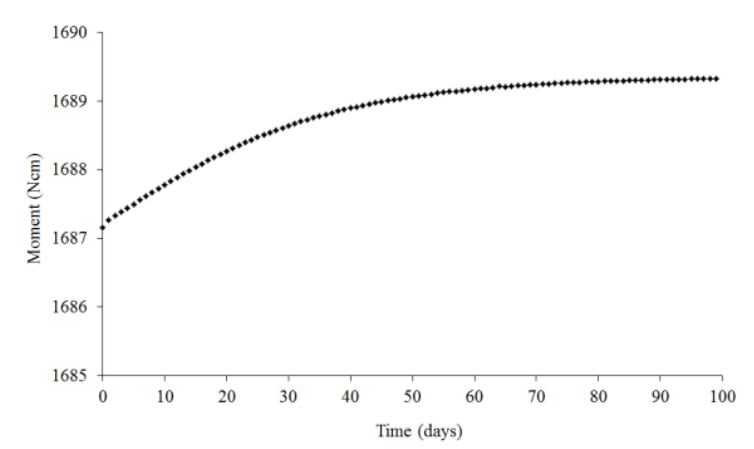

Fig. 14 Bending moment for $S_{3}$ point of the frame - time

Results show that bending moment value for the midpoint of the beam of the frame decreases with time under sustained loading. However, bending moment of the column sections, which are for $300 \mathrm{~mm}$ lower from beamto-column connection and $300 \mathrm{~mm}$ over the base plate of the column, increases. These results shows that timedependent behaviour of GFRP profiles are affecting the structural behaviour of frames. These values present the moment redistribution in viscoelastic member sections of the GFRP frame under long term loads.

\section{Conclusions}

Time-dependent behaviour of GFRP profiles under sustained loads is investigated using both analytical approach and test data. A plane frame made of GFRP profiles is tested under sustained loads and strain, deflections are monitored. Also, an analytical method is presented for 
calculation of strain and deflections for the GFRP frame. Results of the analytical calculation and test data are evaluated and the following conclusions are drawn.

1. Structures that are formed with GFRP profiles are viscoelastic and vertical midpoint deflection are increased $11.5 \%$ for 100 days for the current test. The increase is in lowering trend and this shows the nature of viscoelastic behaviour under sustained loads. Likewise, strain values are monitored from different locations on the frame members and strain values are in the trend of an increase. Strain values, where the vertical displacement is monitored, show an increase of $12.9 \%$ for 100 days at the end of the test.

2. Analytical calculation results show good compliance with full-scale test data in displacement values and also in strain data. The difference between analytical results and test data are not more than $1 \%$ for all compared station points.

3. Since all the sections on a frame cannot be reported from full-scale tests, analytical calculation give engineers an opportunity to foreseen the time-dependent values of displacement and strain for any desired location on the frame. Furthermore, bending moment values can be determined by analytical calculation and structural design can be performed accounting possible time-dependent effects for GFRP frame structures.

4. Bending moment values for GFRP frame member sections, increase or decrease due to time regarding the loading of the frame. However, changes in bending moment values are not more than $1 \%$ for all sections at particular locations of the frame.

5. Since, coupon tests are generally focused in the literature, this study contributes to full-scale tests of the time-dependent behaviour of frame structures formed using GFRP profiles from both analytical and experimental perspective.

\section{References}

1. Bank, L.C. 2006. Composites for Construction: Structural Design with FRP Materials, John Wiley \& Sons, New Jersey, USA, 560 p. http://dx.doi.org/10.1002/9780470121429.

2. Correia, J.R.; Bai, Y.; Keller, T. 2015. A review of the fire behaviour of pultruded GFRP structural profiles for civil engineering applications, Composite Structures 127: $267-287$. http://dx.doi.org/10.1016/j.compstruct.2015.03.006.

3. Feng, P.; Wang, J.; Loughery, D.; Niu, D. 2014. Effects of corrosive environments on properties of pultruded GFRP plates, Composites: Part B 67: 427-433. http://dx.doi.org/10.1016/j.compositesb.2014.08.021.

4. Bai, Y.; Keller, T. 2008. Modal parameter identification for a GFRP pedestrian bridge, Composite Structures 82: 90-100. http://dx.doi.org/10.1016/j.compstruct.2006.12.008.

5. Li, Y.F.; Badjie, S.; Chen, W.W.; Chiu, Y.T. 2014. Case study of first all-GFRP pedestrian bridge in Taiwan, Case Studies in Construction Materials 1: 83-95. http://dx.doi.org/10.1016/j.cscm.2014.05.001.

6. Gonilha, J.A.; Correia, J.R.; Branco, F.A. 2014. Structural behavior of a GFRP-concrete hybrid footbridge prototype: Experimental tests and numerical and analytical simulations, Engineering Structures 60: 11-
22.

http://dx.doi.org/10.1016/j.engstruct.2013.12.018.

7. Clarke, J.L. 1996. EUROCOMP Design Code and Handbook, Structural Design of Polymer Composites, Clarke E\&FN Spon, London.

8. Scott, D.W.; Zureick, A. 1998. Compression creep of a pultruded E-glass/vinylester composite, Composites Science and Technology 98: 1361-1369. http://dx.doi.org/10.1016/S0266-3538(98)00009-8.

9. Mottram, J.T. 1993. Short and long-term structural properties of pultruded beam assemblies fabricated using adhesive bonding, Composite Structures 25:387395 .

http://dx.doi.org/10.1016/0263-8223(93)90186-T.

10. Bottoni, M.; Mazzotti, C.; Savoia, M. 2014. Creep tests on GFRP pultruded specimens subjected to traction or shear, Composite Structures 108: 514-523. http://dx.doi.org/10.1016/j.compstruct.2013.09.057.

11. Bank, L.C.; Mosallam, A.S. 1992. Creep and failure of a full size fiber reinforced plastic pultruded frame, Composite Engineering 2(3): 213-227. http://dx.doi.org/10.1016/0961-9526(92)90005-Q.

12. Secer, M. 2010. Application of a developed stress strain - time relationship for viscoelastic materials on glass fiber reinforced plastic bar systems, Ph.D. Thesis, Dokuz Eylul University, Izmir, Turkey (in Turkish).

13. GFRP Profile Catalogue, Pul-tech FRP Composites.

14. Standard Test Method for Tensile, Compressive, and Flexural Creep and Creep - Rupture of Plastics. Philadelphia, ASTM D2990-01.

15. Standard Test Method for Flexural Properties of Unreinforced and Reinforced Plastics and Electrical Insulating Materials. Philadelphia, ASTM D790-07.

16. Structural Plastics Design Manual, American Society of Civil Engineers, Reston, Virginia, ASCE SPDM-84.

\section{Secer, M.E. Kural}

\section{CREEP BEHAVIOUR OF PLANE FRAME} STRUCTURES MADE OF GFRP PROFILES

\section{S u m m a r y}

A methodology is presented for analytical calculation of creep behavior of plane frames made of glass fiber reinforced polymer (GFRP) profiles and an experimental study is carried out in order to evaluate the analytical calculation results. In order to account nonlinear viscoelastic material behavior, stress - strain - time relationship of plane frame is given and creep behavior of plane frame structure is investigated. Material coefficients for the creep functions are determined using three point beam bending test results. In order to validate the analytical approach, a plane frame made of GFRP profiles is tested under sustained loads for 100 days and displacements, strains are monitored. Strain and displacement values that are calculated using analytical method show good agreement with the full-scale test data.

Keywords: viscoelastic behaviour, creep, glass fiber reinforced polymer profiles, GFRP frame.

Received February 06, 2016

Accepted June 08, 2017 